\title{
PROTEIN KINASE C ISOFORM-DEPENDENT MYOCARDIAL PROTECTION BY ISCHEMIC PRECONDITIONING AND POTASSIUM CARDIOPLEGIA
}

Kejie Lu, MD*

Hajime Otani, MD

Tadashi Yamamura, MD

Yoshihisa Nakao, MD

Reiji Hattori, MD

Hideki Ninomiya, MD

Motohiko Osako, MD

Hiroji Imamura, MD
Objective: Ischemic preconditioning combined with potassium cardioplegia does not always confer additive myocardial protection. This study tested the hypothesis that the efficacy of ischemic preconditioning under potassium cardioplegia is dependent on protein kinase $\mathrm{C}$ isoform.

Methods: Isolated and crystalloid-perfused rat hearts underwent 5 cycles of 1 minute of ischemia and 5 minutes of reperfusion (low-grade ischemic preconditioning) or 3 cycles of 5 minutes of ischemia and 5 minutes of reperfusion (high-grade ischemic preconditioning) or time-matched continuous perfusion. These hearts received a further 5 minutes of infusion of normal buffer or oxygenated potassium cardioplegic solution. The isoform nonselective protein kinase $\mathrm{C}$ inhibitor chelerythrine $(5 \mu \mathrm{mol} / \mathrm{L})$ was administered throughout the preischemic period. All hearts underwent 35 minutes of normothermic global ischemia followed by 30 minutes of reperfusion. Isovolumic left ventricular function and creatine kinase release were measured as the end points of myocardial protection. Distribution of protein kinase $\mathrm{C} \alpha, \delta$, and $\varepsilon$ in the cytosol and the membrane fractions were analyzed by Western blotting and quantified by a densitometric assay.

Results: Low-grade ischemic preconditioning was almost as beneficial as potassium cardioplegia in improving functional recovery; left ventricular developed pressure 30 minutes after reperfusion was $70 \pm 15 \mathrm{~mm} \mathrm{Hg}$ $(P<.01)$ in low-grade ischemic preconditioning and $77 \pm 14 \mathrm{~mm} \mathrm{Hg}$ $(P<.001)$ in potassium cardioplegia compared with values found in unprotected control hearts $(39 \pm 12 \mathrm{~mm} \mathrm{Hg})$. Creatine kinase release during reperfusion was also equally inhibited by low-grade ischemic preconditioning $(18.2 \pm 10.6 \mathrm{IU} / \mathrm{g}$ dry weight, $P<.05)$ and potassium cardioplegia $(17.6 \pm$ $6.7 \mathrm{IU} / \mathrm{g}, P<.01)$ compared with control values. However, low-grade ischemic preconditioning in combination with potassium cardioplegia conferred no significant additional myocardial protection; left ventricular developed pressure was $80 \pm 17 \mathrm{~mm} \mathrm{Hg}$, and creatine kinase release was $14.8 \pm$ $11.0 \mathrm{IU} / \mathrm{g}$. In contrast, high-grade ischemic preconditioning with potassium cardioplegia conferred better myocardial protection than potassium cardioplegia alone; left ventricular developed pressure was $121 \pm 16 \mathrm{~mm} \mathrm{Hg}(P<$ $.001)$, and creatine kinase release was $8.3 \pm 5.8 \mathrm{IU} / \mathrm{g}(P<.05)$. Chelerythrine itself had no significant effect on functional recovery and creatine kinase release in the control hearts, but it did inhibit the salutary effects not only of low-grade and high-grade ischemic preconditioning but also those of potas-
From the Department of Thoracic and Cardiovascular Surgery, Kansai Medical University, Moriguchi City, Osaka, Japan.

Received for publication June 15, 2000; revisions requested July 25, 2000; revisions received Aug 7, 2000; accepted for publication Aug 28, 2000.

Address for reprints: Hajime Otani, MD, Department of Thoracic and Cardiovascular Surgery, Kansai Medical University, 10-15 Fumizono-cho, Moriguchi City, Osaka 570-8507, Japan (E-mail: otanih@takii.kmu.ac.jp).

\footnotetext{
*Present address: The Department of Cardio-thoracic Surgery, Capital University of Medical Science, Beijing Friendship Hospital, Beijing, China.

J Thorac Cardiovasc Surg 2001;121:137-48

Copyright (C) 2001 by The American Association for Thoracic Surgery

0022-5223/2001 $\$ 35.00+0 \quad \mathbf{1 2 / 1 / 1 1 1 2 1 0}$

doi: $10.1067 / \mathrm{mtc} .2001 .111210$
} 
sium cardioplegia. Low-grade ischemic preconditioning and potassium cardioplegia enhanced translocation of protein kinase $\mathrm{C} \alpha$ to the membrane, whereas high-grade ischemic preconditioning also enhanced translocation of protein kinase $C \delta$ and $\varepsilon$. Chelerythrine inhibited translocation of all 3 protein kinase $\mathrm{C}$ isoforms.

Conclusions: These results suggest that myocardial protection by low-grade ischemic preconditioning and potassium cardioplegia are mediated through enhanced translocation of protein kinase $\mathrm{C} \alpha$ to the membrane. It is therefore suggested that activation of the novel protein kinase $\mathrm{C}$ isoforms is necessary to potentiate myocardial protection under potassium cardioplegia. (J Thorac Cardiovasc Surg 2001;121:137-48)

Istitin schemic preconditioning (IPC) is known as a powerful form of endogenous myocardial protection against necrosis, contractile dysfunction, and arrhythmias during ischemia and reperfusion..$^{1-3}$ Although numerous studies have proven the benefit of IPC in myocardial protection in regional or global models of unprotected ischemia, the efficacy of IPC when combined with potassium cardioplegia (PCP) remains controversial. $^{4-9}$ Previous studies, including our own, ${ }^{7,8}$ have demonstrated that IPC and PCP confer an equally beneficial effect on postischemic functional recovery, whereas combination of the 2 techniques afforded no significant additional protection. These studies have suggested that IPC and PCP share a common mechanism for myocardial protection. However, a certain preconditioning challenge could enhance myocardial protection under PCP in the clinical setting. ${ }^{10}$ It is therefore important to elucidate the additional mechanism underlying synergistic myocardial protection by IPC to invent the strategy for myocardial protection during cardiac operations.

IPC is known to be a graded phenomenon in which intracellular signaling pathways and its potency of myocardial protection depend on the duration and number of cycles of ischemia and reperfusion. ${ }^{11-13}$ It is possible that suboptimal IPC protocols against unprotected ischemia do not enhance myocardial protection when combined with PCP because of a common mechanism of protection, whereas optimal IPC protocols against unprotected ischemia may also confer additive myocardial protection under PCP. Although the mechanisms by which IPC produces myocardial protection remain elusive, a growing body of evidence suggests that protein kinase $\mathrm{C}(\mathrm{PKC})$ is involved in myocardial protection induced by IPC. Moreover, it is increasingly clear that different preconditioning stimuli provoke the activation of distinct PKC isoforms, which play a distinct role in myocardial protection. ${ }^{14,15} \mathrm{PKC}$ isoforms in the adult rat heart are subdivided into 3 groups according to the requirement of different cofactors for activation. ${ }^{16} \mathrm{PKC} \alpha, \beta_{1}, \beta_{2}$, and $\gamma$ isoforms require both $\mathrm{Ca}^{2+}$ and lipids (ie, phosphatidylserine and diacylglycerol) for their activation. The subfamily of novel PKC isoforms, which includes PKC $\zeta, \varepsilon, \eta, \theta$, and $\mu$, do not require $\mathrm{Ca}^{2+}$, but as with the classical isoforms, still require lipids for activation. The subfamily of atypical $\mathrm{PKC}$ isoforms includes $\mathrm{PKC} \zeta, \mathrm{l}$, and $\lambda$, which require phosphatidylserine for its activity, but neither $\mathrm{Ca}^{2+}$ nor diacylglycerol are needed for their activation. In the adult rat heart PKC $\alpha, \delta$, and $\varepsilon$ have been considered to be critical mediators for myocardial protection by IPC. ${ }^{17-19}$ These isoforms are translocated to the membrane and activated at different stages of myocardial ischemia and on administration of $\mathrm{Ca}^{2+}$ loading or chemical agonists, such as adenosine and phorbol esters. ${ }^{15,16,20,21}$ Thus, it is anticipated that the efficacy of IPC when combined with PCP is determined by the grade of IPC and is dependent on which PKC isoforms are activated during IPC challenges. Therefore, the present study was undertaken to test this hypothesis by using low-grade or high-grade IPC, which confers suboptimal or optimal myocardial protection, respectively, against unprotected ischemia.

\section{Materials and methods}

Perfusion technique. Male Sprague-Dawley rats weighing 250 to $300 \mathrm{~g}$ were used in the present study. These animals received humane care according to the animal welfare regulations of the Kansai Medical University and were quarantined in quiet quarters for at least a week before the study. The rats were anesthetized intraperitoneally with pentobarbital sodium $(100 \mathrm{mg} / \mathrm{kg})$. After thoracotomy, the hearts were rapidly excised and placed in a Langendorff apparatus. The hearts were perfused at a constant mean pressure of 70 to 75 $\mathrm{mm} \mathrm{Hg}$ with Krebs-Henseleit bicarbonate buffer solution (composition: $118 \mathrm{mmol} / \mathrm{L} \mathrm{NaCl}, 4.7 \mathrm{mmol} / \mathrm{L} \mathrm{KCl}, 1.2$ $\mathrm{mmol} / \mathrm{L} \mathrm{MgSO}_{4}, 25 \mathrm{mmol} / \mathrm{L} \mathrm{NaHCO}_{3}, 1.2 \mathrm{mmol} / \mathrm{L} \mathrm{KH}_{2} \mathrm{PO}_{4}$, 


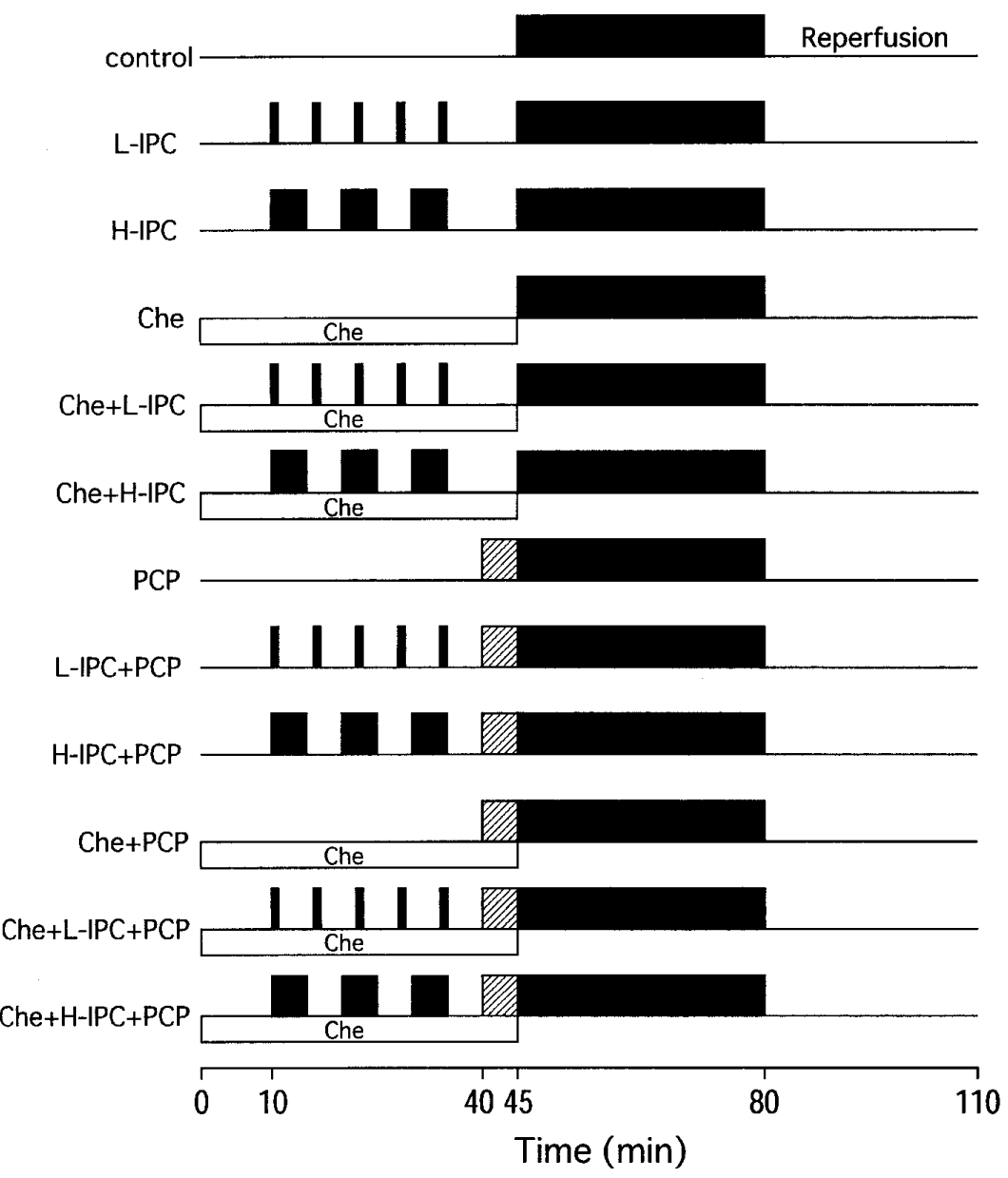

Fig 1. Experimental protocols. $L-I P C$, Low-grade IPC induced by 5 cycles of 1 minute of ischemia and 5 minutes of reperfusion; $H$-IPC, high-grade IPC induced by 3 cycles of 5 minutes of ischemia and 5 minutes of reperfusion; Che, $5 \mu \mathrm{mol} / \mathrm{L}$ chelerythrine. Filled boxes, Ischemia; hatched boxes, oxygenated PCP.

$2.5 \mathrm{mmol} / \mathrm{L} \mathrm{CaCl}_{2}$, and $11 \mathrm{mmol} / \mathrm{L}$ glucose; $\mathrm{pH} 7.4$ ) at $37^{\circ} \mathrm{C}$ when equilibrated with a mixture of $95 \%$ oxygen and $5 \%$ carbon dioxide gas.

During the stabilization period, a latex balloon was inserted into the left ventricle through the left atrium to measure isovolumic left ventricular function. The balloon was filled with saline solution to produce a left ventricular end-diastolic pressure (LVEDP) of 5 to $10 \mathrm{~mm} \mathrm{Hg}$ at baseline, and the balloon volume was kept constant throughout the experiment. Coronary flow $(\mathrm{CF})$ was measured by timed collection of the coronary effluent. Hearts producing a left ventricular developed pressure (LVDP) of lower than $100 \mathrm{~mm} \mathrm{Hg}$ or a heart rate (HR) of less than 240 beats/min at baseline were excluded from the study.

Experimental protocol. The hearts were randomly assigned to 12 groups (Fig 1). Time-matched control hearts underwent 45 minutes of normal perfusion before 35 minutes of normothermic global ischemia (unprotected ischemia) followed by 30 minutes of reperfusion. Low-grade or high- grade IPC was induced by 5 cycles of 1 minute of ischemia and 5 minutes of reperfusion or 3 cycles of 5 minutes of ischemia and 5 minutes of reperfusion, respectively. In these groups of hearts the last reperfusion of IPC before the sustained period of ischemia was extended to 10 minutes to match the time frame with the hearts in the PCP groups. The hearts in the PCP groups received 40 minutes of normal perfusion followed by 5 minutes of infusion of potassium-rich Krebs-Henseleit bicarbonate buffer solution (containing 20 $\mathrm{mmol} / \mathrm{L} \mathrm{KCl}$ with equimolar reduction of $\mathrm{NaCl}$ ) equilibrated with a mixture of $95 \%$ oxygen and $5 \%$ carbon dioxide gas, $\mathrm{pH} 7.4$, before the sustained period of ischemia. Low-grade or high-grade IPC was also introduced in these groups of hearts before receiving PCP. The isoform nonselective PKC inhibitor chelerythrine (Research Biochemical International Inc, Natick, Mass) at a concentration of $5 \mu \mathrm{mol} / \mathrm{L}$, which is known to inhibit PKC activity specifically, was administered for 45 minutes before 35 minutes of ischemia in all the chelerythrine-treated groups. 
Table I. Effect of IPC on cardiac performance

\begin{tabular}{|c|c|c|c|c|c|}
\hline & \multirow[b]{2}{*}{ Baseline } & \multirow[b]{2}{*}{ Before ischemia } & \multicolumn{3}{|c|}{ Reperfusion (min) } \\
\hline & & & 10 & 20 & 30 \\
\hline \multicolumn{6}{|l|}{ LVDP (mm Hg) } \\
\hline Control $(\mathrm{n}=7)$ & $126 \pm 13$ & $126 \pm 9$ & $27 \pm 10$ & $36 \pm 12$ & $39 \pm 12$ \\
\hline L-IPC (n = 6) & $125 \pm 14$ & $119 \pm 15$ & $54 \pm 14^{*}$ & $63 \pm 15^{\dagger}$ & $70 \pm 15 \dagger$ \\
\hline H-IPC $(n=6)$ & $119 \pm 11$ & $78 \pm 8 \ddagger$ & $70 \pm 19 \neq$ & $81 \pm 18$ & $87 \pm 12$ \% \\
\hline Che $(n=6)$ & $121 \pm 9$ & $130 \pm 9$ & $28 \pm 16$ & $41 \pm 15$ & $44 \pm 16$ \\
\hline Che + L-IPC $(n=6)$ & $127 \pm 15$ & $130 \pm 8$ & $31 \pm 18 \S$ & $42 \pm 18$ & $44 \pm 19 \S$ \\
\hline Che + H-IPC $(n=6)$ & $128 \pm 10$ & $100 \pm 19 * \S$ & $38 \pm 21 \S$ & $48 \pm 19 \S$ & $50 \pm 17 \|$ \\
\hline \multicolumn{6}{|l|}{ HR (beats/min) } \\
\hline Control & $298 \pm 30$ & $298 \pm 28$ & $188 \pm 29$ & $190 \pm 25$ & $193 \pm 23$ \\
\hline L-IPC & $298 \pm 14$ & $296 \pm 14$ & $225 \pm 34$ & $232 \pm 36^{*}$ & $233 \pm 35^{*}$ \\
\hline H-IPC & $303 \pm 23$ & $276 \pm 16$ & $217 \pm 30$ & $223 \pm 24^{*}$ & $225 \pm 27 *$ \\
\hline Che & $296 \pm 26$ & $294 \pm 19$ & $194 \pm 33$ & $197 \pm 32$ & $197 \pm 29$ \\
\hline Che + L-IPC & $300 \pm 18$ & $300 \pm 18$ & $188 \pm 33$ & $201 \pm 24$ & $204 \pm 18$ \\
\hline Che + H-IPC & $305 \pm 27$ & $298 \pm 20$ & $205 \pm 53$ & $213 \pm 48$ & $218 \pm 43$ \\
\hline \multicolumn{6}{|c|}{$\mathrm{CF}\left(\mathrm{mL} \cdot \mathrm{min}^{-1} \cdot \mathrm{g}^{-1}\right.$ dry weight $)$} \\
\hline Control & $58 \pm 6$ & $59 \pm 6$ & $45 \pm 6$ & $48 \pm 6$ & $48 \pm 5$ \\
\hline L-IPC & $59 \pm 5$ & $69 \pm 6^{*}$ & $58 \pm 8 \dagger$ & $61 \pm 7 \dagger$ & $61 \pm 8 \dagger$ \\
\hline H-IPC & $57 \pm 7$ & $79 \pm 11 \dagger$ & $65 \pm 7 \ddagger$ & $67 \pm 7 \ddagger$ & $67 \pm 6 \ddagger$ \\
\hline Che & $61 \pm 7$ & $65 \pm 5$ & $46 \pm 6$ & $49 \pm 6$ & $49 \pm 6$ \\
\hline Che + L-IPC & $63 \pm 7$ & $70 \pm 9^{*}$ & $48 \pm 5 \S$ & $50 \pm 6 \S$ & $50 \pm 6 \S$ \\
\hline Che + H-IPC & $58 \pm 8$ & $84 \pm 10 \neq$ & $49 \pm 6$ & $52 \pm 6$ & $52 \pm 6$ \\
\hline \multicolumn{6}{|l|}{ LVEDP (mm Hg) } \\
\hline Control & $7 \pm 2$ & $7 \pm 2$ & $65 \pm 10$ & $55 \pm 11$ & $51 \pm 10$ \\
\hline L-IPC & $8 \pm 2$ & $8 \pm 2$ & $43 \pm 11 \dagger$ & $35 \pm 6 \dagger$ & $32 \pm 6 \dagger$ \\
\hline H-IPC & $7 \pm 1$ & $7 \pm 1$ & $32 \pm 7 \ddagger$ & $27 \pm 6 \ddagger$ & $26 \pm 6 \neq$ \\
\hline Che & $7 \pm 2$ & $7 \pm 2$ & $58 \pm 11$ & $52 \pm 9$ & $47 \pm 10$ \\
\hline Che + L-IPC & $8 \pm 2$ & $7 \pm 2$ & $57 \pm 9 \S$ & $48 \pm 10 \S$ & $46 \pm 10 \S$ \\
\hline Che + H-IPC & $8 \pm 2$ & $8 \pm 2$ & $53 \pm 11 \|$ & $45 \pm 11 \|$ & $42 \pm 11 \S$ \\
\hline
\end{tabular}

Data are expressed as mean $\pm \mathrm{SD}$. $L$-IPC, Low-grade IPC; $H$-IPC, high-grade IPC; Che, chelerythrine.

$* P<.05, \dagger P<.01$, and $\ddagger P<.001$ compared with control hearts.

$\S P<.05$ and $\| P<.01$ compared with respective IPC without Che.

Coronary effluent was collected during 30 minutes of reperfusion, and creatine kinase activity was measured by an enzymatic assay method ${ }^{22}$ to assess the severity of myocardial injury. At the end of the experiment, a piece of the left ventricular tissue was excised to determine the wet/dry ratio.

In the experiments on PKC assay, left ventricular myocardium of approximately $500 \mathrm{mg}$ was excised at the end of IPC, PCP, or time-matched normal perfusion. The myocardial samples were immediately frozen in liquid nitrogen and kept at $-80^{\circ} \mathrm{C}$ until use.

Tissue sample preparation. Frozen myocardial tissue samples were powdered under liquid nitrogen and homogenized in 5 volumes of buffer containing $320 \mathrm{mmol} / \mathrm{L}$ sucrose, $10 \mathrm{mmol} / \mathrm{L}$ Tris- $\mathrm{HCl}, 1 \mathrm{mmol} / \mathrm{L}$ ethyleneglycol-bis- $(\beta-$

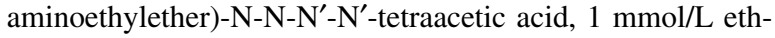
ylenediamine tetraacetic acid, $10 \mathrm{mmol} / \mathrm{L}$ benzamidine, 50 $\mathrm{mmol} / \mathrm{L} \mathrm{NaF}, 50 \mu \mathrm{g} / \mathrm{mL}$ phenylmethylsulfonyl fluoride, 10 $\mu \mathrm{g} / \mathrm{mL}$ aprotinin, $10 \mu \mathrm{g} / \mathrm{mL}$ leupeptin, $10 \mu \mathrm{g} / \mathrm{mL}$ pepstatin $\mathrm{A}$, and $0.3 \% \beta$-mercaptoethanol with a Polytron homogenizer (Brinkman Instruments, Inc, Westbury, NY) at the maximum speed 3 times for 15 seconds each. The homogenates were mixed with an equal volume of the same buffer and centrifuged at $1000 \mathrm{~g}$ for 10 minutes, and then the supernatant was centrifuged at $100,000 \mathrm{~g}$ for 60 minutes. The $100,000 \mathrm{~g}$ pellet was designated the membrane fraction, whereas the $100,000 \mathrm{~g}$ supernatant was referred to as the cytosol fraction. Protein concentrations were determined by the method of Bradford $^{23}$ by means of an assay kit (Bio-Rad Laboratories, Yokohama, Japan).

Immunoblotting and quantification of PKC. The fractions were subjected to sodium dodecylsulfate-polyacrylamide gel electrophoresis in $7.5 \%$ polyacrylamide gels and then immunoblotted according to the method of Yoshida and associates. ${ }^{24}$ The blots were blocked with $5 \%$ skim milk in buffer containing $150 \mathrm{mmol} / \mathrm{L} \mathrm{NaCl}, 10 \mathrm{mmol} / \mathrm{L}$ Tris- $\mathrm{HCl}$ (pH 7.4), and $0.05 \%$ Tween-20 for at least 1 hour and then incubated with one of the 2000- to 3000-fold diluted antibodies against $\mathrm{PKC}$ isoforms for 1 hour at room temperature, and the PKC isoforms were visualized by the use of an ECL Western blotting detection kit. The amounts of PKC isoforms on the immunoblots were measured with a densitometric analysis by use of the NIH Image program (NIH-Image ver- 
Table II. Effect of IPC and PCP on cardiac performance

\begin{tabular}{|c|c|c|c|c|c|}
\hline & \multirow[b]{2}{*}{ Baseline } & \multirow[b]{2}{*}{ Pre-PCP } & \multicolumn{3}{|c|}{ Reperfusion (min) } \\
\hline & & & 10 & 20 & 30 \\
\hline \multicolumn{6}{|l|}{ LVDP (mm Hg) } \\
\hline Control $(\mathrm{n}=7)$ & $126 \pm 13$ & $126 \pm 9$ & $27 \pm 9$ & $36 \pm 12$ & $39 \pm 12$ \\
\hline $\mathrm{PCP}(\mathrm{n}=7)$ & $123 \pm 13$ & $125 \pm 11$ & $61 \pm 19 \dagger$ & $72 \pm 16 \ddagger$ & $77 \pm 14 \div$ \\
\hline L-IPC + PCP $(n=6)$ & $129 \pm 15$ & $126 \pm 15$ & $63 \pm 19 \dagger$ & $77 \pm 16 \neq$ & $80 \pm 17 \ddagger$ \\
\hline H-IPC + PCP $(n=6)$ & $120 \pm 10$ & $76 \pm 15 \ddagger, \mathscr{I}$ & $108 \pm 22 \ddagger$ & $123 \pm 21$ \$, I & $121 \pm 16 \ddagger, \mathscr{I}$ \\
\hline $\mathrm{Che}+\mathrm{PCP}(\mathrm{n}=6)$ & $124 \pm 10$ & $127 \pm 7$ & $31 \pm 18 \S$ & $47 \pm 19 \S$ & $52 \pm 16 \S$ \\
\hline Che + L-IPC + PCP $(n=6)$ & $130 \pm 12$ & $128 \pm 12$ & $39 \pm 15 \S$ & $53 \pm 12 *, \S, \#$ & $56 \pm 10^{*}, \S, \#$ \\
\hline Che + H-IPC + PCP $(n=6)$ & $126 \pm 15$ & $103 \pm 14^{*}, \S, \#$ & $51 \pm 12 \dagger, \dagger \dagger$ & $70 \pm 19 \dagger, \dagger \dagger$ & $74 \pm 10+, \dagger \dagger$ \\
\hline \multicolumn{6}{|l|}{ HR (beats/min) } \\
\hline Control & $298 \pm 30$ & $298 \pm 28$ & $188 \pm 29$ & $190 \pm 25$ & $193 \pm 23$ \\
\hline $\mathrm{PCP}$ & $301 \pm 14$ & $298 \pm 29$ & $209 \pm 57$ & $232 \pm 42 *$ & $234 \pm 39 *$ \\
\hline L-IPC + PCP & $295 \pm 31$ & $293 \pm 21$ & $203 \pm 35$ & $240 \pm 36^{*}$ & $242 \pm 35^{*}$ \\
\hline $\mathrm{H}-\mathrm{IPC}+\mathrm{PCP}$ & $302 \pm 29$ & $299 \pm 23$ & $276 \pm 36 \$$ & $276 \pm 50 \ddagger, \S$ & $289 \pm 60 \ddagger, \S$ \\
\hline Che + PCP & $299 \pm 18$ & $297 \pm 16$ & $184 \pm 37$ & $189 \pm 33 \#$ & $189 \pm 30 \#$ \\
\hline Che + L-IPC + PCP & $302 \pm 20$ & $300 \pm 22$ & $182 \pm 40$ & $196 \pm 34 \#$ & $196 \pm 36 \#$ \\
\hline Che + H-IPC + PCP & $305 \pm 27$ & $298 \pm 25$ & $221 \pm 16 \#$ & $226 \pm 15 \#$ & $229 \pm 14^{*}, \#$ \\
\hline \multicolumn{6}{|l|}{$\mathrm{CF}\left(\mathrm{mL} \cdot \mathrm{min}^{-1} \cdot \mathrm{g}^{-1}\right.$ dry weight $)$} \\
\hline Control & $58 \pm 6$ & $59 \pm 6$ & $45 \pm 6$ & $48 \pm 6$ & $48 \pm 5$ \\
\hline PCP & $60 \pm 6$ & $60 \pm 5$ & $58 \pm 7 \dagger$ & $59 \pm 9^{*}$ & $58 \pm 7 \dagger$ \\
\hline L-IPC + PCP & $61 \pm 5$ & $68 \pm 6^{*}, \S$ & $61 \pm 7 \dagger$ & $62 \pm 7 \dagger$ & $61 \pm 7 \dagger$ \\
\hline H-IPC + PCP & $62 \pm 8$ & $76 \pm 10 \dagger$ & $62 \pm 5 \ddagger$ & $63 \pm 4 \ddagger$ & $64 \pm 3 \ddagger$ \\
\hline $\mathrm{Che}+\mathrm{PCP}$ & $60 \pm 8$ & $65 \pm 8$ & $49 \pm 6$ & $49 \pm 6 \S$ & $49 \pm 6 \S$ \\
\hline Che + L-IPC + PCP & $60 \pm 9$ & $70 \pm 10^{*}, \S$ & $51 \pm 9$ & $50 \pm 8 \#$ & $51 \pm 9 \#$ \\
\hline Che + H-IPC + PCP & $61 \pm 9$ & $82 \pm 11 \ddagger, \pi$ & $54 \pm 5^{*}, \#$ & $55 \pm 5 \#$ & $55 \pm 5^{* *}$ \\
\hline \multicolumn{6}{|l|}{ LVEDP (mm Hg) } \\
\hline Control & $7 \pm 2$ & $7 \pm 2$ & $65 \pm 10$ & $55 \pm 11$ & $50 \pm 10$ \\
\hline $\mathrm{PCP}$ & $6 \pm 2$ & $6 \pm 2$ & $36 \pm 11 \neq$ & $35 \pm 9 \dagger$ & $31 \pm 9 \dagger$ \\
\hline L-IPC + PCP & $6 \pm 1$ & $6 \pm 1$ & $33 \pm 7 \ddagger$ & $27 \pm 5 \ddagger$ & $24 \pm 5 \neq$ \\
\hline $\mathrm{H}-\mathrm{IPC}+\mathrm{PCP}$ & $6 \pm 2$ & $6 \pm 1$ & $20 \pm 8 \ddagger$ & $16 \pm 9 \neq$ & $11 \pm 6 \neq$ \\
\hline $\mathrm{Che}+\mathrm{PCP}$ & $7 \pm 2$ & $7 \pm 2$ & $58 \pm 12$ & $52 \pm 13 \S$ & $48 \pm 12 \S$ \\
\hline $\mathrm{Che}+\mathrm{L}-\mathrm{IPC}+\mathrm{PCP}$ & $7 \pm 2$ & $7 \pm 2$ & $55 \pm 12 \S, * *$ & $46 \pm 12 * *$ & $41 \pm 11 * *$ \\
\hline $\mathrm{Che}+\mathrm{H}-\mathrm{IPC}+\mathrm{PCP}$ & $7 \pm 2$ & $7 \pm 2$ & $50 \pm 14 *, *, *$ & $36 \pm 15^{*}, *$ & $33 \pm 15^{*}, * *$ \\
\hline
\end{tabular}

Data are expressed as mean $\pm \mathrm{SD}$.

$L$-IPC, Low-grade IPC; $H$-IPC, high-grade IPC; $C h e$, chelerythrine.

$* P<.05, \dagger P<.01$, and $\ddagger P<.001$ compared with control hearts.

$\S P<.05, \| P<.01$, and $\llbracket P<.001$ compared with respective IPC without chelerythrine.

$\# P<.05, * * P<.01$, and $\dagger \dagger P<.001$ compared with PCP among the PCP-treated groups.

sion 1.59). Consistency in the data analysis was ensured by running the cytosolic and membrane fractions of all 5 tissue samples in each group on the same gel. Each immunoblotting experiment was repeated twice, and the results were averaged. The total amounts of protein transferred from each lane to the nitrocellulose membranes during blotting were rarely identical, despite a careful attempt to achieve equal protein loading in all lanes of the gel, and therefore each PKC isoform signal was normalized to the corresponding Coomassie Blue stain signal determined by densitometric analysis, as described by Ping and coworkers. ${ }^{25}$ Rabbit polyclonal antibodies against PKC isoforms $\alpha, \delta$, and $\varepsilon$ were obtained from Santa Cruz Biotechnology Inc (Santa Cruz, Calif). Relative distribution of each PKC isoform in the membrane fraction was calculated by dividing the normalized PKC isoform signal in the membrane fraction by the normalized PKC isoform signal in the cytosol fraction. The values were presented as a percentage of the cytosol fraction.

Statistical analysis. All data are expressed as means \pm SD. Statistical analysis was performed by using 1-way analysis of variance and the Scheffé multiple comparison test.

\section{Results}

Effect of IPC on cardiac performance. Table I shows the effect of low- or high-grade IPC without PCP on cardiac performance in the isolated rat heart. None of the baseline hemodynamic variables significantly differed among the 6 groups. LVDP was significantly depressed by highgrade IPC but not by low-grade IPC. The recovery of LVDP during reperfusion was significantly greater in the 


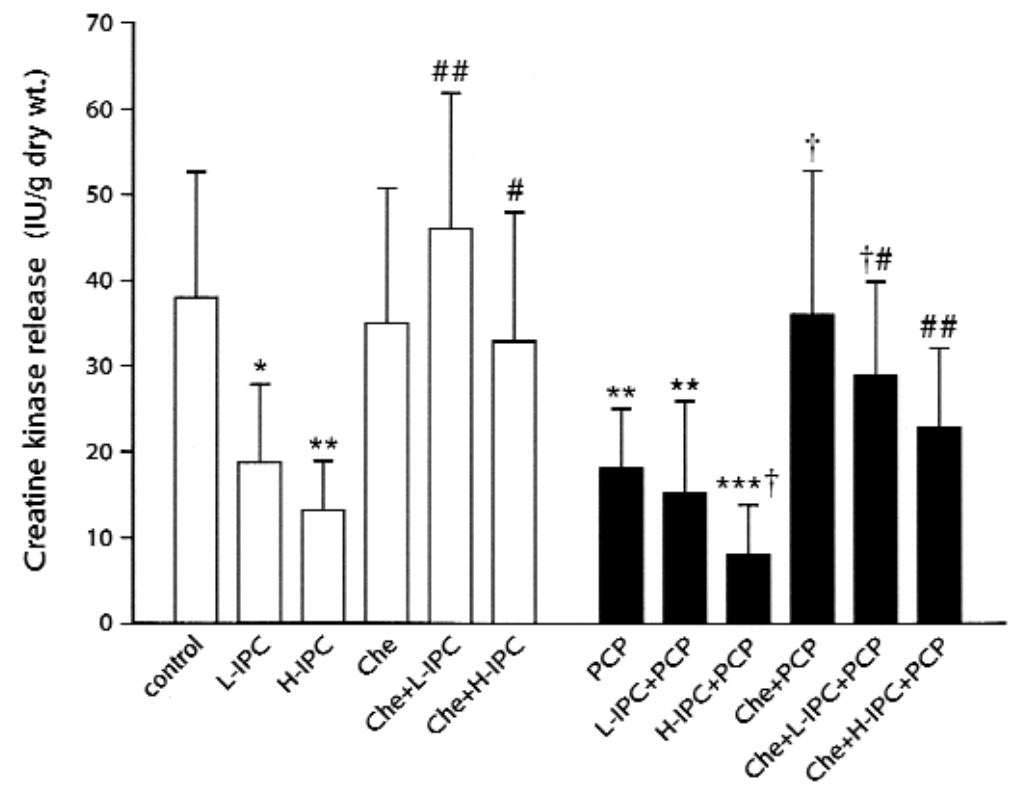

Fig 2. Creatine kinase release. Creatine kinase activities were measured in coronary effluent collected during 30 minutes of reperfusion. $L-I P C$, Low-grade IPC; $H$-IPC, high-grade IPC; $C h e, 5 \mu \mathrm{mol} / \mathrm{L}$ chelerythrine. Each $b a r$ graph represents mean $\pm \mathrm{SD}$ of 7 experiments (control and $\mathrm{PCP}$ ) or 6 experiments. $* P<.05, * * P<.01$, and $* * * P$ $<.001$ compared with control. $\# P<.05$ and \#\#P<.01 compared with respective IPC without chelerythrine. $\dagger P<$ .05 compared with PCP.

hearts with low-grade IPC than in control hearts, and the recovery was further enhanced by high-grade IPC. Chelerythrine had no significant effect on LVDP in the normally perfused hearts but significantly reversed the depression of LVDP after high-grade IPC. Although pretreatment with chelerythrine alone had no significant effect on the recovery of LVDP during reperfusion compared with that of control hearts, chelerythrine abolished the improvement of LVDP recovery conferred by low- or high-grade IPC during reperfusion.

HR was not affected during either grade of IPC. The recovery of HR during reperfusion was significantly greater in the hearts with low- or high-grade IPC compared with that in control hearts. The improvement of HR recovery conferred by IPC was abolished by pretreatment with chelerythrine.

CF was significantly increased by both grades of IPC, and the increase in $\mathrm{CF}$ was more prominent with highgrade than low-grade IPC. CF recovery during reperfusion was significantly greater in the hearts with low- or high-grade IPC compared with that in control hearts. Chelerythrine had no significant effect on CF in the normally perfused hearts or the hearts undergoing IPC. However, pretreatment with chelerythrine significantly inhibited the improvement of CF recovery conferred by both grades of IPC during reperfusion.
LVEDP remained unchanged after either grade of IPC. During reperfusion, both grades of IPC decreased LVEDP significantly compared with values in control hearts, although high-grade IPC was more effective in lowering LVEDP. Pretreatment with chelerythrine had no significant effect on LVEDP during reperfusion in the hearts without IPC. Chelerythrine, however, abolished the LVEDP-lowering effect of IPC.

Effect of IPC and PCP on cardiac performance. Table II shows the effect of PCP combined with or without IPC on cardiac performance in the isolated rat heart. Hemodynamic data of the control hearts shown in Table I were used for the comparison between unprotected ischemia and PCP. Preischemic variables of cardiac performance by treatment with low- or high-grade IPC with or without chelerythrine was comparable with those observed in the hearts that did not undergo PCP. The recovery of LVDP during reperfusion was significantly greater in the hearts with PCP compared with that in control hearts, but there was no further improvement in LVDP when combined with low-grade IPC. In contrast, the enhanced recovery of LVDP conferred by PCP during reperfusion was significantly potentiated by high-grade IPC. The improvement of LVDP recovery conferred by PCP in combination with or without IPC was significantly inhibited by pretreatment with chelerythrine. 
Table III. Time to contracture, time to peak of contracture, peak contracture, and end-ischemic contracture

\begin{tabular}{|c|c|c|c|c|}
\hline & $\begin{array}{l}\text { TTC } \\
(\mathrm{min})\end{array}$ & $\begin{array}{l}T P C \\
(\min )\end{array}$ & $\begin{array}{l}\text { Peak contracture } \\
(\mathrm{mm} \mathrm{Hg})\end{array}$ & $\begin{array}{l}\text { End-ischemic contracture } \\
\qquad(\mathrm{mm} \mathrm{Hg})\end{array}$ \\
\hline Control (n = 7) & $12.6 \pm 1.8$ & $20.3 \pm 2.4$ & $49 \pm 5$ & $44 \pm 7$ \\
\hline L-IPC (n=6) & $8.3 \pm 0.9 \ddagger$ & $14.9 \pm 1.7 \ddagger$ & $56 \pm 5^{*}$ & $50 \pm 9$ \\
\hline H-IPC (n=6) & $6.2 \pm 1.0$ 丰 & $12.2 \pm 1.4 \ddagger$ & $59 \pm 5 \dagger$ & $52 \pm 7$ \\
\hline Che $(n=6)$ & $12.3 \pm 2.0$ & $20.8 \pm 2.2$ & $54 \pm 6$ & $50 \pm 8$ \\
\hline Che + L-IPC $(n=6)$ & $6.6 \pm 1.2 \ddagger, \S$ & $11.5 \pm 1.2 \ddagger$ & $64 \pm 7 \dagger, \S$ & $55 \pm 7^{*}$ \\
\hline Che + H-IPC $(n=6)$ & $4.7 \pm 0.6 \neq, \S$ & $9.7 \pm 0.8 \ddagger$ & $70 \pm 7 \ddagger, \S$ & $60 \pm 8 \dagger$ \\
\hline $\mathrm{PCP}(\mathrm{n}=7)$ & $20.5 \pm 2.1 \ddagger$ & $27.4 \pm 3.0 \ddagger$ & $38 \pm 7 \dagger$ & $34 \pm 6^{*}$ \\
\hline L-IPC + PCP $(n=6)$ & $15.0 \pm 1.6^{*}, \dagger \dagger$ & $21.8 \pm 1.7^{* *}$ & $47 \pm 6 \#$ & $43 \pm 4 \#$ \\
\hline H-IPC + PCP $(n=6)$ & $14.5 \pm 1.8 \dagger \dagger$ & $20.7 \pm 1.9 \dagger \dagger$ & $50 \pm 5^{* *}$ & $45 \pm 7 \#$ \\
\hline Che + PCP $(n=6)$ & $15.8 \pm 2.0 * * *$ & $21.9 \pm 1.9^{* *}$ & $49 \pm 5 \#$ & $44 \pm 7 \#$ \\
\hline Che + L-IPC + PCP $(n=6)$ & $11.8 \pm 1.2 \|, \dagger \dagger$ & $18.8 \pm 1.31, \dagger \dagger$ & $54 \pm 5 \S, * *$ & $46 \pm 5 \#$ \\
\hline Che + H-IPC + PCP $(n=6)$ & $11.5 \pm 1.9 \S, \dagger \dagger$ & $18.0 \pm 2.2,, \dagger \dagger$ & $58 \pm 7^{*}, \S, \dagger \dagger$ & $50 \pm 4 * *$ \\
\hline
\end{tabular}

Data are expressed as mean $\pm \mathrm{SD}$. $L-I P C$, Low-grade IPC; $H-I P C$, high-grade IPC; Che, chelerythrine.

$* P<.05, \dagger P<.01$, and $\ddagger P<.001$ compared with control hearts.

$\S P<.5, \mid P<.1$, and $\mathbb{I} P<.001$ compared with respective IPC without chelerythrine.

$\# P<.05, * * P<.01$, and $\dagger \dagger P<.001$ compared with PCP among the PCP-treated groups.

The recovery of HR during reperfusion was significantly greater in the hearts with PCP compared with that in control hearts. Low-grade IPC failed to enhance the recovery of HR conferred by PCP. However, highgrade IPC was capable of potentiating the recovery of HR conferred by PCP. Pretreatment with chelerythrine abolished the recovery of HR during reperfusion in the hearts with PCP in combination with or without IPC.

$\mathrm{CF}$ recovery during reperfusion was significantly greater in the hearts with PCP compared with that in control hearts. No further increase in CF during reperfusion was noted when combined with low-grade IPC. In contrast, PCP preceded by high-grade IPC significantly increased $\mathrm{CF}$ during reperfusion compared with PCP alone or in combination with low-grade IPC. Pretreatment with chelerythrine significantly inhibited the improvement of CF recovery conferred by PCP in combination with or without IPC.

LVEDP was significantly lower in the hearts treated with PCP during reperfusion compared with that in control hearts. Low-grade IPC, however, failed to enhance the LVEDP-lowering effect of PCP during reperfusion. In contrast, high-grade IPC potentiated the LVEDP-lowering effect of PCP during reperfusion. Pretreatment with chelerythrine significantly reversed the LVEDP-lowering effect of PCP combined with or without IPC.

Effect of IPC and PCP on time to onset of contracture, time to peak of contracture, and peak contracture. We analyzed the time course and magnitude of ischemic contracture in an attempt to solve an issue of qualitative difference between IPC and PCP because
IPC and PCP produce a differential effect on the occurrence of ischemic contracture despite a comparable cardioprotective effect. ${ }^{26}$ Time to onset of ischemic contracture (TTC) was defined as the time after ischemia to reach an increase of $5 \mathrm{~mm} \mathrm{Hg}$ in LVEDP from the preischemic value. TTC was significantly shortened by low-grade and high-grade IPC compared with TTC of control hearts (Table III). Pretreatment with chelerythrine significantly potentiated IPCinduced shortening of TTC. In contrast, PCP significantly prolonged TTC compared with TTC in control hearts. Low-grade and high-grade IPC significantly shortened PCP-induced prolongation of TTC. Pretreatment with chelerythrine significantly shortened TTC after PCP in combination with or without IPC.

Similarly, time to peak of contracture (TPC) was significantly shortened by low-grade and high-grade IPC and was significantly prolonged by PCP compared with TPC in control hearts. Pretreatment with chelerythrine significantly potentiated IPC-induced shortening of TPC and reversed PCP-induced prolongation of TPC.

Peak contracture was significantly enhanced by IPC compared with that of control hearts and was potentiated by pretreatment with chelerythrine. PCP significantly mitigated peak contracture compared with that found in control hearts. However, PCP-induced amelioration of peak contracture was reversed by pretreatment with chelerythrine.

Ischemic contracture was gradually attenuated after reaching peak contracture in all the hearts. However, the magnitude of contracture at the end of ischemia 

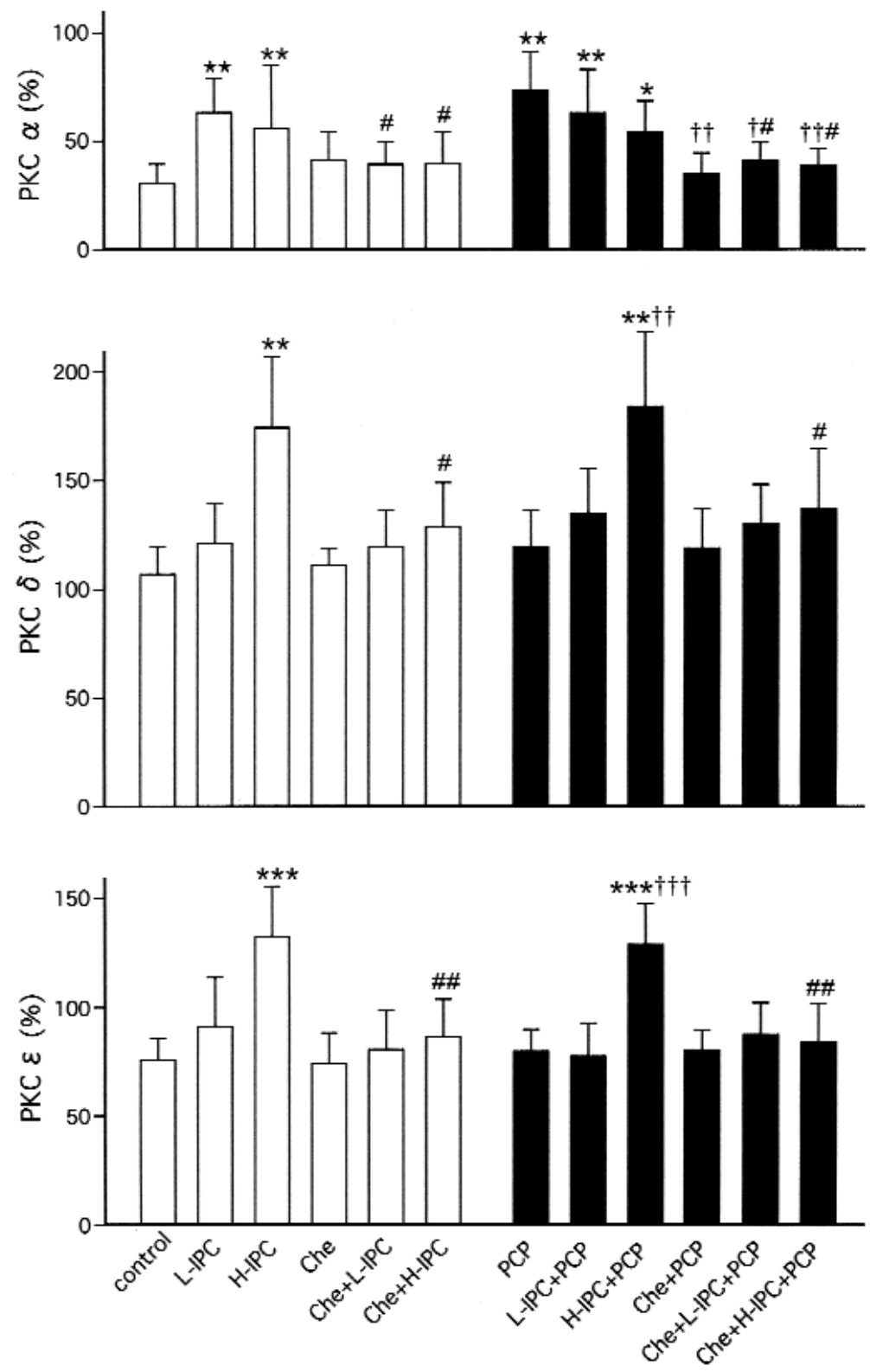

Fig 3. PKC isoform distribution. Relative distribution of $\mathrm{PKC} \alpha, \delta$, and $\varepsilon$ in the membrane fraction over the cytosol fraction was calculated as described in the "Materials and methods" section. Open bars, Experimental groups without PCP; filled bars, experimental groups with PCP. L-IPC, Low-grade IPC; H-IPC, high-grade IPC; Che, 5 $\mu \mathrm{mol} / \mathrm{L}$ chelerythrine. Each bar graph expresses mean $\pm \mathrm{SD}$ of 5 experiments. $* P<.05, * * P<.01$, and $* * * P<$ .001 compared with control hearts. $\# P<.05$ and \#\#P<.01 compared with respective IPC without chelerythrine. $\dagger P<.05, \uparrow \uparrow P<.01$, and $\dagger \uparrow \uparrow P<.001$ compared with PCP.

remained significantly greater in the hearts pretreated with chelerythrine and IPC compared with that found in the control hearts. It also remained significantly greater in the hearts undergoing PCP pretreated with IPC in the presence or absence of chelerythrine compared with PCP alone.
Effect of IPC on creatine kinase release. Creatine kinase release during reperfusion was significantly inhibited by low-grade or high-grade IPC compared with that of control hearts (Fig 2). Chelerythrine alone had no significant effect on creatine kinase release during reperfusion. However, inhibition of creatine kinase 
release conferred by IPC was reversed by pretreatment with chelerythrine. Creatine kinase release was also significantly inhibited by PCP. However, combination with low-grade IPC failed to enhance the inhibition of creatine kinase release conferred by PCP. In contrast, high-grade IPC was capable of potentiating creatine kinase release inhibition conferred by PCP. Pretreatment with chelerythrine reversed creatine kinase release inhibition conferred by PCP and both grades of IPC.

Effect of IPC and PCP on membrane translocation of PKC isoforms. The effect of IPC on translocation of PKC isoforms to the membrane just before 35 minutes of ischemia is illustrated in Fig 3. Both lowand high-grade IPC significantly increased distribution of $\mathrm{Ca}^{2+}$-dependent PKC isoform $\alpha$ in the membrane fraction. However, only high-grade IPC was capable of redistributing $\mathrm{Ca}^{2+}$-independent $\mathrm{PKC}$ isoforms $\delta$ and $\varepsilon$ to the membrane. Chelerythrine inhibited translocation of PKC $\alpha$ to the membrane in the hearts with low-grade IPC. Chelerythrine also inhibited translocation of all of 3 PKC isoforms to the membrane in the hearts with high-grade IPC.

Membrane translocation of PKC was also assessed in the hearts with PCP. It was found that PCP alone increased distribution of PKC $\alpha$ to the membrane. There was no further increase in distribution of PKC $\alpha$ to the membrane by preceding low-grade IPC. Highgrade IPC followed by PCP, however, significantly increased distribution of PKC $\delta$ and $\varepsilon$ to the membrane in addition to PKC $\alpha$. Chelerythrine inhibited translocation of PKC $\alpha$ to the membrane in the hearts undergoing PCP with or without preceding low-grade IPC and all $3 \mathrm{PKC}$ isoforms in the hearts with preceding high-grade IPC.

\section{Discussion}

The efficacy of IPC on myocardial protection under PCP has been a matter of debate. ${ }^{4-9}$ The inability of IPC to confer additive myocardial protection when combined with PCP may have been due to inappropriate IPC challenges. Use of a too-short period of ischemia as an IPC protocol cannot produce IPC signaling strong enough to induce myocardial protection. On the other hand, repeating an extended period of ischemia as an IPC protocol deteriorates the recovery of myocardial function by simply imposing excessive ischemic stress before a sustained period of ischemia. Therefore, it is extremely important that any IPC protocols should be proven to be effective in the experimental models with unprotected ischemia before application to PCP. However, IPC protocols that are capable of inducing significant myocardial protection against unprotected ischemia have been found to confer no additional myocardial protection when combined with PCP. ${ }^{7,8}$ Therefore the present study was undertaken to investigate the mechanism underlying differences in the efficacy of IPC on myocardial protection when combined with PCP. The major finding of the present study was that low-grade IPC induced by 5 cycles of 1 minute of ischemia and 5 minutes of reperfusion failed to enhance functional improvement and creatine kinase release inhibition conferred by PCP, whereas highgrade IPC induced by 3 cycles of 5 minutes of ischemia and 5 minutes of reperfusion potentiated functional recovery and creatine kinase release inhibition over PCP alone. This observation indicates that only highgrade IPC can enhance myocardial protection conferred by PCP. Five cycles of 1 minute of ischemia and 5 minutes of reperfusion was chosen as a low-grade IPC because this protocol matches a time frame of high-grade IPC induced by 3 cycles of 5 minutes of ischemia, which is known to induce optimum cardioprotection in a number of animal models. A variety of experimental protocols could induce low-grade or high-grade IPC, although the duration and number of cycles of ischemia and reperfusion to induce low-grade or high-grade IPC may differ between species and experimental models.

The failure of low-grade IPC to enhance myocardial protection induced by PCP and the ability of highgrade IPC to potentiate it have suggested that lowgrade IPC and PCP share a common mechanism of myocardial protection, whereas high-grade IPC provokes additional mechanisms. It is now evident that PKC plays a pivotal role in IPC-mediated myocardial protection. ${ }^{26,27}$ The participation of $\mathrm{PKC}$-mediated intracellular events in IPC-induced myocardial protection has been suggested by studies with structurally distinct PKC inhibitors, such as chelerythrine, calphostin $\mathrm{C}$, and bisindolylmaleimide, which have consistently inhibited IPC-induced myocardial protection with some exceptions. ${ }^{18}$ Although those PKC inhibitors are relatively specific for PKC compared with the nonspecific protein kinase inhibitor staurosporine, none of them possess apparent $\mathrm{PKC}$ isoform selectivity. ${ }^{28}$ Thus, the chelerythrine used in the present study was expected to inhibit all the PKC isoforms tested. Moreover, the variety of intracellular events provoked by PKC are known to be isoform dependent in that individual $\mathrm{PKC}$ isoforms could play a distinct role in myocardial protection. For example, $\mathrm{Ca}^{2+}$-dependent PKC isoform $\alpha$ is activated by IPC, phorbol esters, and $\mathrm{Ca}^{2+}{ }^{29}$ The present study has also provided the evi- 
dence that PCP alone induces translocation of PKC $\alpha$ to the membrane, and chelerythrine completely abrogated myocardial protection afforded by PCP. The mechanism for PCP-induced activation of PKC $\alpha$ is not clear at present but is probably mediated by a transient increase in intracellular $\mathrm{Ca}^{2+}$. It has been demonstrated that bolus infusion of a high concentration of $\mathrm{CaCl}_{2}$ into the coronary arteries or a brief period of $\mathrm{Ca}^{2+}$ depletion and $\mathrm{Ca}^{2+}$ repletion (induction of $\mathrm{Ca}^{2+}$ paradox) confers myocardial protection against ischemic injury. ${ }^{29,30} \mathrm{~A}$ high extracellular potassium content is also known to increase intracellular $\mathrm{Ca}^{2+}$ through voltage-dependent $\mathrm{Ca}^{2+}$ channels. ${ }^{31,32}$ Our previous study demonstrated that PCP provoked a transient increase in intracellular $\mathrm{Ca}^{2+}$ that significantly inhibited an increase in intracellular $\mathrm{Ca}^{2+}$ during subsequent cardioplegic preservation and reperfusion in the intact guinea pig heart. ${ }^{33}$ Thus, a transient increase in intracellular $\mathrm{Ca}^{2+}$ and subsequent activation of PKC $\alpha$ before a sustained period of ischemia may be a common denominator of myocardial protection induced by low-grade IPC and PCP. However, PKC $\alpha$ activation is transient, and its efficacy on myocardial protection may be limited, whereas activation of the $\mathrm{Ca}^{2+}$-independent PKC isoforms $\delta$ and $\varepsilon$ is long lasting. ${ }^{17} \mathrm{~A}$ number of recent studies have substantiated the critical importance of PKC $\delta$ and $\varepsilon$ in mediating cardiomyocyte protection against hypoxia- or ischemia-induced cell death. ${ }^{14,25,35,36}$ Our study demonstrating that only highgrade IPC activated PKC $\delta$ and $\varepsilon$ and conferred superior myocardial protection over low-grade IPC also points to the same conclusion.

Although the present study has suggested that myocardial protection conferred by low-grade IPC and PCP is mediated at least in part by the same mechanism (ie, $\mathrm{Ca}^{2+}$-dependent PKC activation), the functional consequence during ischemia was markedly different between IPC and PCP. PCP delays, and IPC accelerates, ischemic contracture. Such enhanced ischemic contracture after IPC has already been documented by Otani and coworkers ${ }^{8}$ and Kolocassides and coworkers. ${ }^{7}$ Because these studies demonstrated no apparent correlation between the magnitude of ischemic contracture and ultimate myocardial protection, the significance of delaying ischemic contracture in myocardial protection under PCP remains unknown. However, the delayed occurrence of ischemic contracture by PCP is likely to be related to preservation of adenosine triphosphate (ATP) caused by rapid cessation of electrical and mechanical activities in light of the fact that ischemic contracture is induced primarily by depletion of ATP. ${ }^{37}$ However, our study has raised the possibility that PKC $\alpha$ activation is involved in the alleviation of ischemic contracture because pretreatment with chelerythrine accelerated ischemic contracture induced by low-grade and high-grade IPC and reversed the contracture-ameliorating effect of PCP, although it is unclear whether PKC $\alpha$ activation promotes ATP preservation. ATP preservation may be crucial in myocardial protection particularly in the hearts with high-grade IPC, given that high-grade IPC depletes ATP more drastically than low-grade IPC before a sustained period of ischemia that could discount the efficacy of high-grade IPC. Thus, high-grade IPC followed by oxygenated PCP resumes myocardial ATP before a sustained period of ischemia. This assumption may explain why highgrade IPC in combination with PCP conferred superior myocardial protection over high-grade IPC alone despite an equivalent magnitude of activation of all the $\mathrm{PKC}$ isoforms.

Another important finding of our study is that highgrade IPC gave rise to a significant decrease of LVDP during the IPC challenge, and chelerythrine reversed the depression of LV contractility. This observation indicates that high-grade IPC-inducible activation of PKC is involved in myocardial stunning. Because the mechanism of myocardial stunning associated with a brief period of ischemia remains elusive, participation of PKC in myocardial stunning warrants further investigation.

Limitations of the study. Although the present study has demonstrated IPC grade-dependent enhancement of myocardial protection under PCP, there are concerns as to whether the same phenomenon takes place in a wide variety of species and experimental models. Isoforms of PKC activated in response to ischemia are known to be different among the species. Unlike in rats, IPC induces selective translocation of PKC $\varepsilon$ and $\eta$ in rabbits. ${ }^{25}$ The PKC isoforms that are activated by IPC and are responsible for myocardial protection remain unknown in human subjects. Developmental differences in regulation of PKC isoforms should also be considered..$^{14}$ In addition, the temperature that we have studied is normothermia throughout the experiment. In the majority of cardiac operations, human hearts undergo some sort of hypothermic protection. Such a difference in myocardial temperature during PCP and ischemia may influence the response to IPC because PKC activation is temperature dependent. Modality of PCP may also affect the efficacy of combined IPC treatment on myocardial protection. Our study used 5 minutes of infusion of normothermic oxygenated crystalloid PCP. This modality of PCP mimics, but is not identical to, that introduced in warm blood cardioplegia. Oxygenated and substrate-rich PCP solutions could resume a myocardial energy level depleted by prior IPC challenges, as mentioned before, which 
confer more salutary effects on myocardial protection than introducing IPC in combination with nonoxygenated PCP solutions. Finally, validity of interpretations of the present data critically relies on the specificity of the PKC inhibitor chelerythrine. Although the concentration of chelerythrine used in our study is known to be specific for PKC inhibition, involvement of unknown effects of chelerythrine in modulation of IPC- and PCP-induced myocardial protection cannot be ruled out. Further studies with isoform-specific PKC inhibitors or PKC gene-modified animals will be necessary to address this issue.

Clinical implications. Numerous investigators have attempted to take advantage of IPC for myocardial protection during coronary angioplasty and coronary artery bypass operation. ${ }^{38}$ However, the efficacy of IPC in the clinical setting of coronary interventions has not been clearly delineated. Although our present study indicates that low-grade IPC may be useful, at least during coronary interventions, such as coronary angioplasty and off-pump coronary artery bypass operation that do not make use of PCP, using high-grade IPC to enhance myocardial protection under PCP may not be encouraged in clinical practice. This is because the graded phenomenon of IPC has not been demonstrated in human subjects, and clinical trials to identify optimal IPC protocols may be limited from an ethical point of view. For this reason, greater effort should be exerted to invent pharmacologic tools that are capable of inducing activation of $\mathrm{Ca}^{2+}$-independent $\mathrm{PKC}$ isoforms to enhance myocardial protection under PCP. Pharmacologic preconditioning with adenosine has been shown to be efficacious in myocardial protection under PCP. ${ }^{10}$ This enhanced myocardial protection by adenosine may be attributed to activation of PKC $\delta .{ }^{39}$ It has also been reported that 1,4-benzothiazepine derivative JTV519 confers a strong protective effect against $\mathrm{Ca}^{2+}$ overload-induced myocardial injury through specific activation of the PKC $\delta$ isoform in the rat ventricular myocardium. ${ }^{40}$ In addition, PKC $\varepsilon$ activators, such as phorbol esters, epinephrine, and endothelin, ${ }^{16}$ may be used for pharmacologic preconditioning under PCP. Better understanding of the molecular biology of PKC signaling would allow development of improved preconditioning strategies for cardiac operations.

\section{REFERENCES}

1. Murry CE, Jennings RB, Reimer KA. Preconditioning with ischemia: a delay of lethal cell injury in ischemic myocardium. Circulation 1986;74:1124-36.

2. Steenbergen C, Perlman M, London R, Murphy E. Mechanism of preconditioning: ionic alterations. Circ Res 1993;72:112-25.

3. Hagar J, Hale S, Kloner R. Effect of preconditioning ischemia on reperfusion arrhythmias after coronary artery occlusion and reperfusion in the rat. Circ Res 1991;68:61-8.

4. Illes RW, Wright JK, Inners-McBride K, Yang C-J, Tristan A. Ischemic preconditioning improves preservation with crystalloid cardioplegia. Ann Thorac Surg 1994;58:1481-5.

5. Zellner JL, Hebbar L, Crawford FA Jr, Mukherjee R, Spinale FG. Beneficial effects of myocyte preconditioning on contractile processes after cardioplegic arrest. Ann Thorac Surg 1996;61:558-64.

6. Bolling SF, Olszanski DA, Childs KF, Gallagher KP, Ning XH. Stunning, preconditioning, and functional recovery after global myocardial ischemia. Ann Thorac Surg 1994;58:822-7.

7. Kolocassides KG, Galinanes M, Hearse DJ. Ischemic preconditioning, cardioplegia or both? J Mol Cell Cardiol 1994;26:1411-4.

8. Otani H, Kawasaki H, Ninomiya Y, Kido M, Kawaguchi H, Osako M, et al. Effects of ischemic preconditioning on the recovery of myocardial function after unprotected ischemia and cardioplegia in the isolated and crystalloid-perfused rat hearts. Jpn J Thorac Cardiovasc Surg 1997;45:23-30.

9. Perraut LP, Menasche P, Bel A, de Chaumaray T, Peynet J, Mondry A, et al. Ischemic preconditioning in cardiac surgery: a word of caution. J Thorac Cardiovasc Surg 1996;112:1378-86.

10. Mentzer Jr RM, Birjiniuk V, Khuri S, Lowe JE, Rahko PS, Weisel $\mathrm{RD}$, et al. Adenosine myocardial protection. Ann Surg 1999;229:643-50.

11. Lawson CS, Coltart JC, Hearse DJ. Dose-dependent and temporal characteristics of protection by ischemic preconditioning against ischaemia-induced arrhythmias in rat hearts. J Mol Cell Cardiol 1993;25:1391-402.

12. Schulz R, Post H, Vahlhaus C, Heusch G. Ischemic preconditioning in pigs: a graded phenomenon. Circulation 1998;98:1022-9.

13. Fryer RM, Schultz JEJ, Hsu AK, Gross GJ. Importance of PKC and tyrosine kinase in single or multiple cycles of preconditioning in rat hearts. Am J Physiol 1999;276:H1229-35.

14. Puceat M, Hilal-Dandan R, Strulovici B, Brunton LL, Brown JH. Differential regulation of protein kinase $\mathrm{C}$ isoforms in isolated neonatal and adult rat cardiomyocytes. J Biol Chem 1994;269:16938-44.

15. Meldrum DR, Cleveland JC, Meng X, Sheriden BC, Gamboni F, Cain BS, et al. Protein kinase $\mathrm{C}$ isoform diversity in preconditioning. J Surg Res 1997;69:183-7.

16. Bogoyevitch MA, Parker PJ, Sugden PH. Characterization of protein kinase $\mathrm{C}$ isotype expression in adult rat heart. Circ Res 1993;72:757-67.

17. Kawamura S, Yoshida K, Miura T, Mizukami Y, Matsuzaki M. Ischemic preconditioning translocates PKC- $\delta$ and $-\varepsilon$, which mediate functional protection in isolated rat heart. Am J Physiol 1998;275:H2266-71.

18. Albert CJ, Ford DA. Protein kinase C translocation and PKCdependent protein phosphorylation during myocardial ischemia. Am J Physiol 1999;286:H642-50.

19. Yoshida K, Mizukami Y, Kitakaze M. Nitric oxide mediates protein kinase $\mathrm{C}$ isoform translocation in rat heart during postischemic reperfusion. Biochim Biophys Acta 1999;1453:230-8.

20. Meldrum DR, Cleveland JC, Mitchell MB, Sheridan BC, Gamboni-Robertson F, Harken AH, et al. Protein kinase C mediates $\mathrm{Ca}^{2+}$-induced cardioprotection to ischemia-reperfusion injury. Am J Physiol 1996;271:R718-26.

21. Yoshida K, Kawamura S, Mizukami Y, Kitakaze M. Implication of protein kinase $C-\alpha, \delta$, and $\varepsilon$ isoforms in ischemic preconditioning in perfused rat hearts. J Biochem 1997;122:506-11.

22. Oliver IT. A spectrophotometric method for the determination of 
creatine phosphokinase and myokinase. Biochem J 1955;61:11622.

23. Bradford MM. A rapid and sensitive method for the quantitation of microgram quantities of protein utilizing the principle of protein-dye binding. Anal Biochem 1976;72:248-54.

24. Yoshida K, Hirata T, Akita Y, Mizukami Y, Yamaguchi K, Sorimachi $\mathrm{Y}$, et al. Translocation of protein kinase $\mathrm{C}-\alpha, \delta$ and $\varepsilon$ isoforms in ischemic rat. Biochim Biophys Acta 1996;1317:36-44.

25. Ping P, Zhang J, Qiu Y, Tang XL, Manchikalapudi S, Cao X, et al. Ischemic preconditioning induces selective translocation of protein kinase $C$ isoform $\varepsilon$ and $\eta$ in the heart of conscious rabbits without subcellular redistribution of total protein kinase $\mathrm{C}$ activity. Circ Res 1997;81:404-14.

26. Brooks G, Hearse DJ. Role of protein kinase $\mathrm{C}$ in ischemic preconditioning: player or spectator? Circ Res 1996;79:627-30.

27. Simkhovich BZ, Przyklenk K, Kloner RA. Role of protein kinase $\mathrm{C}$ as a cellular mediator of ischemic preconditioning: a critical review. Cardiovasc Res 1998;40:9-22.

28. Erdbrugger W, Keffel J, Knocks M, Otto T, Philipp T, Michel MC. Protein kinase $\mathrm{C}$ isoenzymes in rat and human cardiovascular tissues. Br J Pharmacol 1997;120:177-86.

29. Miyazaki H, Zhou X, Ashraf M. Calcium preconditioning elicits strong protection against ischemic injury via protein kinase $\mathrm{C}$ signaling pathway. Circ Res 1996;79:137-46.

30. Meldrum DR, Cleveland JC, Sheridan B, Rowland RT, Banerjee A, Harken AH. Cardiac preconditioning with calcium: clinically accessible myocardial protection. J Thorac Cardiovasc Surg 1996;112:778-6.

31. Cyran SE, Ditty SE, Baylen BG, Cheung J, LaNoue KF. Developmental difference of cytosolic free calcium to potassium depolarization and cardioplegia in cardiac myocytes. J Mol Cell Cardiol 1992;24:1167-77.
32. Lopez JR, Jahangir A, Shen WK, Terzic A. Potassium channel openers prevent potassium-induced calcium loading of cardiac cells: possible implication in cardioplegia. J Thorac Cardiovasc Surg 1996;112:820-31.

33. Kato Y, Otani H, Tanaka K, Saito Y, Fukunaka M, Imamura H. Effect of cardioplegic preservation on intracellular calcium transients. Ann Thorac Surg 1991;52:979-86.

34. Meldrum DR, Cleveland JC, Meng X, Sheriden BC, Gamboni F, Cain $\mathrm{B}$, et al. Protein kinase $\mathrm{C}$ isoform diversity in preconditioning. J Surg Res 1997;69:183-7.

35. Gray MO, Karliner JS, Mochly-Rosen D. A selective $\varepsilon$-protein kinase $\mathrm{C}$ antagonist inhibits protection of cardiac myocytes from hypoxia-induced cell death. J Biol Chem 1997;272:30945-51.

36. Liu GS, Cohen MV, Mochly-Rosen D, Downey JM. Protein kinase $\mathrm{C}-\varepsilon$ is responsible for the protection of preconditioning in rabbit cardiomyocytes. J Mol Cell Cardiol 1999;31:1937-48.

37. Koretsune Y, Marban E. Mechanism of ischemic contracture in ferret hearts: relative roles of $\mathrm{Ca}^{2+}{ }_{\mathrm{i}}$ elevation and ATP depletion. Am J Physiol 1990;258:H9-16.

38. Tomai F, Crea F, Chiariello L, Gioffre PA. Ischemic preconditioning in humans: models, mediators, and clinical evidence. Circulation 1999;100:559-63.

39. Henry P, Demolombe S, Escande D. Adenosine A1 stimulation activates delta-protein kinase $\mathrm{C}$ in rat ventricular myocytes. Circ Res 1996;78:161-5.

40. Inagaki K, Kihara Y, Hayashida W, Izumi T, Iwanaga Y, Yoneda $\mathrm{T}$, et al. Anti-ischemic effect of a novel cardioprotective agent, JTV519, is mediated through specific activation of d-isoform of protein kinase $\mathrm{C}$ in rat ventricular myocardium. Circulation 2000;101:797-804.

\section{Targeted}

The Journal of Thoracic and Cardiovascular Surgery gives you two tables of contents.

The condensed table of contents tells you at a glance what topics and authors are presented each month. The expanded table of contents gives you a brief abstract of each article. You select only those articles of most interest to you for further reading. 